\title{
Failure stress criterion for adhesively bonded joint at different strain rates by using dynamic Arcan test device
}

\author{
Ludovic Dufour $^{1, a}$, Benjamin Bourel ${ }^{2}$, Franck Lauro $^{1}$, Gregory Haugou $^{1}$, Nicolas Leconte $^{1}$, and Nicolas Carrere ${ }^{2}$ \\ ${ }^{1}$ University of Valenciennes and Hainaut Cambrésis, LAMIH, UMR CNRS 8201, 59313 Valenciennes, France \\ ${ }^{2}$ ENSTA Bretagne, LBMS EA 4325, 29806 Brest Cedex 9, France
}

\begin{abstract}
The purpose of this work is to determine the failure criterion evolution of assembly bonded with a strain rate dependent adhesive. A new modified ARCAN device is then designed to obtain the average stress at failure under different loading angles and for strain up to $350 \mathrm{~s}^{-1}$. Tests are performed on a hydraulic jack machine and a Digital Image Correlation measurement is used to control the opening and the sliding displacements of the two substrates.
\end{abstract}

\section{Introduction}

In order to achieve better fuel economy, the automotive industry is moving towards the use of lightweight materials, such as polymer/composites, in primary structural components. So, structural bonding often becomes an alternative solution to replace traditional assembly techniques. However, the successful integration of bonding materials in the automotive sector, and particularly for crash loading applications, requires a better understanding of their failure mechanisms at different strain rates. In finite element softwares, failure is mainly managed by three kinds of criteria based on a critical stress, a critical strain or a combination of the previous criteria by a critical energy. A brief summary of the major failure criteria is given below.

For the stress based criteria, the maximum principal stress is mainly used for very brittle materials $[1,2]$ (since cracks initiate and propagate in a direction normal to these maximum principal stresses). Shear stress has also been extensively used to predict lap joint strength [3]. Other stress-based criteria, like the von Mises form has been used by Ikegami et al. [4] to study the strength of scarf joints between glass fibre composites and metals.

For ductile materials, strain criteria generally replace stress criteria, since joints can still carry large loads after adhesive yielding. Adams and Harris [5] used the maximum principal strain as the failure criterion for predicting joint strength. The maximum shear strain is also used in reference [6]. Da Silva et al. show that this criterion is very accurate for single lap joints assemblies [7].

Criteria based on strain energy are a combination of critical stress and strain criteria. They are generally more suitable since all the stress and strain components are taken into account. The energy approach derives from the Griffith's theory, where the failure mechanism is related to strain energy release rate $G_{c}$. Energy release

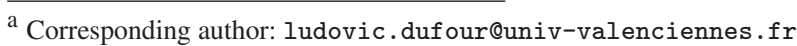

rate of mode-I and mode-II can be obtained respectively from the Double Cantilever Beam (DCB) test and the End Notched Flexure (ENF) test. In the context of the automotive crash, the main difficulty comes from setting up these tests at high strain rates. In reference [8], Joudon et al. develop an experimental procedure to characterize the dynamic fracture toughness of advanced epoxy resins under dynamic loadings.

In the literature, still few studies deal with the strain rate dependence of the failure criterion. Some stress/strain based criteria are proposed, like the one extracted from Johnson and Cook works [9]. In reference [10], a mixedmode failure criterion with strain rate dependency have been proposed for spot welds. In reference [11], Morin and al propose an equivalent failure strain which evolves with the triaxiality stress ratio and the strain rate.

Failure of adhesive is often characterized by assembly tests. Due to the simplicity to set it up, the most used tests are the simple lap shear and double lap shear test. But these tests provide a global response coming from both the behaviours of the adhesive and substrate. To obtain an intrinsic behaviour of the adhesive, it is then better to use a device with rigid substrate (Scarf, Butt joint, TAST, etc.). But for these tests, results in terms of failure depend on the edge effects. Otherwise, for crashworthiness, it is important to characterize adhesive for mixed mode loading and for a large range of loading velocities up to failure of the adhesive without edge effects. In this work, a new test device is proposed to characterize the failure initiation of a thick bonding joint under mixed mode loading, up to high strain rate.

The ultimate aim of this work is to propose a new strain based criterion with strain rate dependence. However, since the local strain being hardly measurable inside a very small joint thickness $(0.3 \mathrm{~mm}$ in this study), the use of a numerical FE model is needed. Through this paper, the criterion will be presented to be a stress based criterion. By knowing the average stress in the adhesive, and consequently the load applied to make the assembly fail, it will be subsequently possible to recalculate the local

This is an Open Access article distributed under the terms of the Creative Commons Attribution License 4.0, which permits unrestricted use, distribution, and reproduction in any medium, provided the original work is properly cited. 


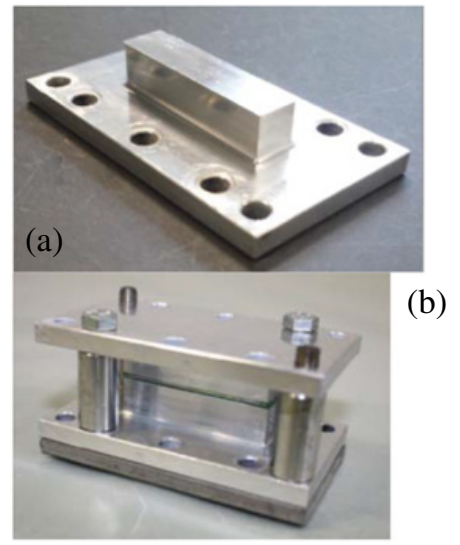

Figure 1. (a) Substrate, (b) positioning device for the bonding process.

failure strain thanks to a FE model, in which the adhesive behaviour is finely defined for a large strain rate range [12].

Then, this new failure criterion will be used to enrich the special cohesive element developed in reference [13].

\section{Experimental device}

To characterize the failure of the adhesive, an Arcan device is developed to obtain the mean stress state at failure with different loading angles $\left(0^{\circ} ; 30^{\circ} ; 45^{\circ} ; 60^{\circ} ; 90^{\circ}\right)$. This device is based on the modified Arcan fixture developed in [14] for quasi-static loads. The special feature of this new device falls within its low mass that required to obtain a noiseless dynamic response, i.e. an effort measurement not disturbed by the system resonance. It is composed by two substrates in aluminium (AU4G) bonded together with a bonding surface of $400 \mathrm{~mm}^{2}$ (Fig. 1a).

For the bonded process, a specific device is designed to put one substrate relatively to the other one with a good thickness control. The substrates assembly is obtained with two centring pins and the thickness control with four spacers (Fig. 1b). After polymerisation, the thickness is checked with a calibrated binocular microscope. For all the specimens, a $0.3 \mathrm{~mm}( \pm 0.05 \mathrm{~mm})$ thickness is obtained.

The identification of the stress failure criteria depends on the accuracy at which the stress field is captured at the failure time. To obtain the best result, two conditions must be obtained. First, the stress state must be as much as possible homogeneous along the bonding joint and through the thickness. And secondly, the failure must occur inside the adhesive to be cohesive type. In order to obtain these conditions, the geometry of the substrates has to compensate the edge effects that makes a stress concentration and so in an early failure initiation in the assembly. Consequently, a beak all along the substrate is used according to previous studies performed by ENSTA laboratory [12] (Fig. 2).

In order to design the geometry of this beak, the simulation of a tensile test at $0^{\circ}$ is carried out with Abaqus in plane strain with a fine mesh on a half model. The substrates are in Aluminium AU4G ( $\mathrm{E}=75 \mathrm{Gpa}$, $v=0.33$ ). The Epoxy Betamate 1822 adhesive is modelled by an elasto-plastic behaviour law obtained by tensile test on bulk specimens. The optimised beak shape leads to a

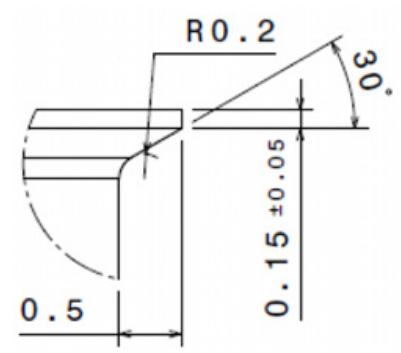

(a)

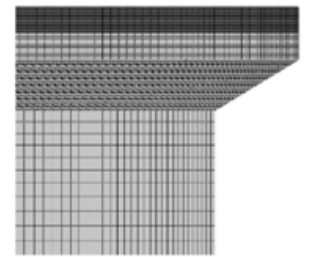

(b)

Figure 2. (a) Beak geometry, (b) Mesh of the beak.

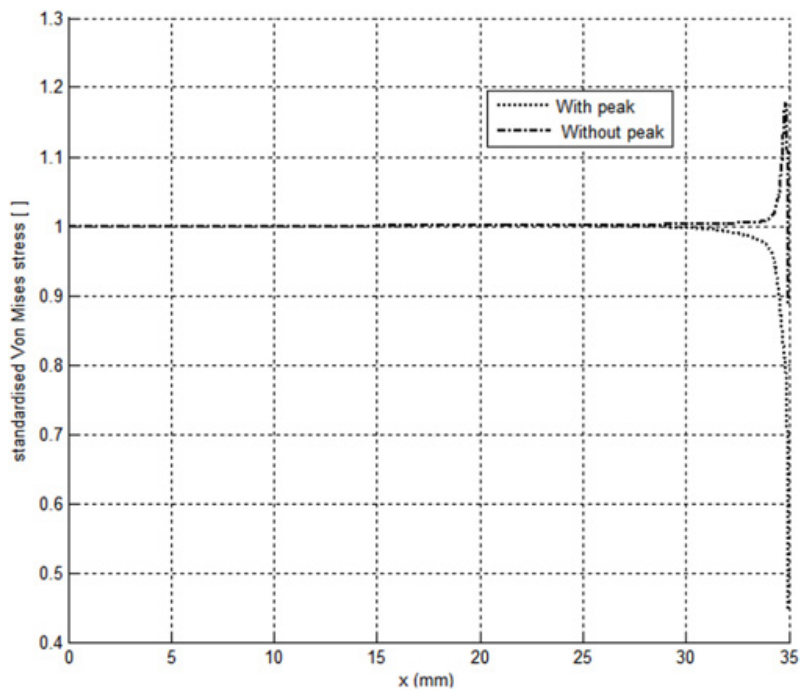

Figure 3. Normalized stress state in the mean plane of the adhesive: reduction of the edge effect by using a beak.

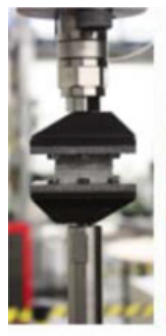

$0^{\circ}$

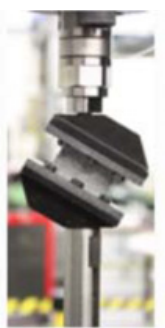

$30^{\circ}$

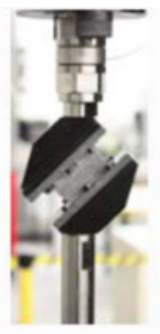

$45^{\circ}$

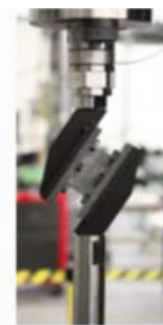

$60^{\circ}$

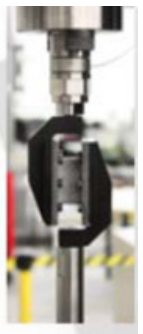

$90^{\circ}$
Figure 4. Dynamic Arcan devices.

deformed shape of the substrates which minimize the stress concentrations (Fig. 3) and allow a homogeneous stress state in the mean plane of the adhesive.

The substrates bonded together are then fixed on rigid supports. The supports are designed for different loading angles and to avoid resonance (Fig. 4).

\section{Experimental study}

\subsection{Testing devices}

The study is performed for an epoxy Betamate1822 from DOW Automotive. The thickness of the bonded joint is $0.3 \mathrm{~mm}$ and the polymerisation conditions are: $23 \mathrm{~min}$ from $70{ }^{\circ} \mathrm{C}$ to $200^{\circ} \mathrm{C}$ and then $20 \mathrm{~min}$ at $200^{\circ} \mathrm{C}$. 


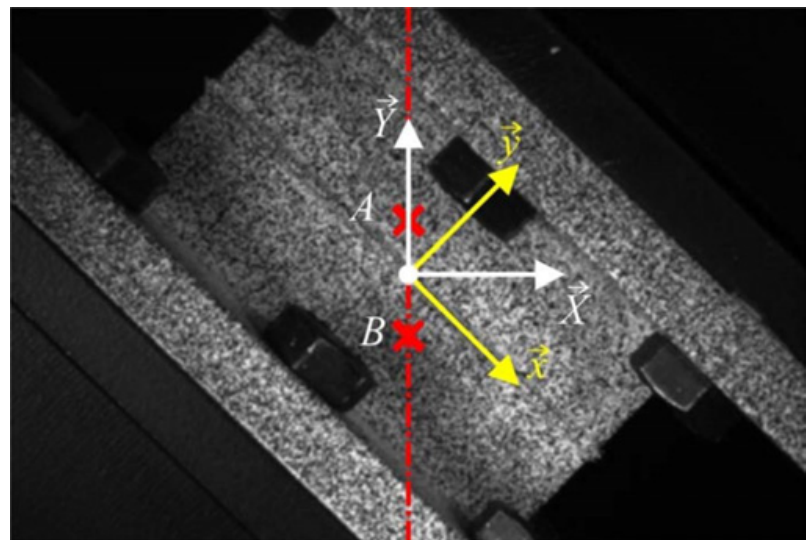

Figure 5. Post-processing by digital image correlation.

Some experiments are carried out with a tensile static machine SYNTECH 20D with an imposed load velocity of $0.5 \mathrm{~mm} / \mathrm{min}$ for angles of $0^{\circ}, 45^{\circ}$ and $90^{\circ}$ and with a dynamic tensile machine INSTRON VHS with imposed load velocity of $1 \mathrm{~mm} / \mathrm{s}, 10 \mathrm{~mm} / \mathrm{s}$ and $100 \mathrm{~mm} / \mathrm{s}$ for angles of $0^{\circ}, 45^{\circ}$ and $90^{\circ}$. The force is measured by a KESTLER $30 \mathrm{KN}$ uniaxial cell force, and the relative displacement of the substrates is measured with non- contact measurement technique by Digital Image Correlation.

\subsection{Analysis}

The pictures obtained by the high speed camera are postprocessed with the software VIC2D in order to measure the displacement of the substrates. The direct measurement on the bonded joint is not possible due to its small thickness. The relative displacements are then measured on substrates according to $Y$-axis (loading direction). According to a rigid substrate assumption, the measurements of the displacement are done on the top substrate at point A and on the bottom substrate at point $B$ (Fig. 5). $D N$ and $D T$ respectively are the normal relative displacement, and the tangential relative displacement between $A$ and $B$ according to the $x$ and $y$ frame. $F N$ and $F T$ are the corresponding normal and tangential strength to the adhesive bond.

The strain rates are then obtained from relative displacements $D N$ and $D T$ by the following expressions:

$$
\begin{aligned}
& \dot{\varepsilon}_{y y}=\frac{d}{d t}\left(\ln \left(1+\frac{D N}{e}\right)\right) \\
& \dot{\varepsilon}_{x y}=\frac{d}{d t}\left(\frac{1}{2} \tan ^{-1}\left(\frac{D T}{e}\right)\right)
\end{aligned}
$$

with $e$ the adhesive thickness.

\subsection{Results}

In all the experiments, the failure of the bonded joint occurs in the joint and corresponds to a cohesive failureas shown in Fig. 6.

The mixed mode failure surface obtained from different loading velocities is presented in Fig. 7. The results show a good repeatability of failure stress for the entire experimental campaign. The normal failure stress

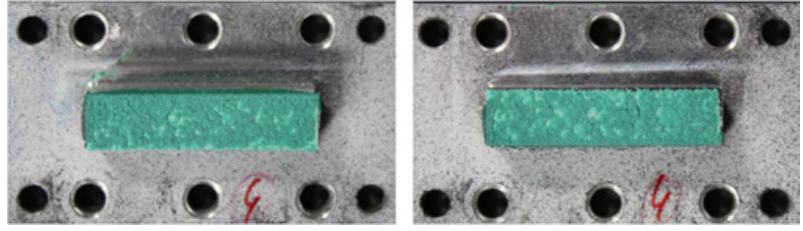

Figure 6. Cohesive failure.

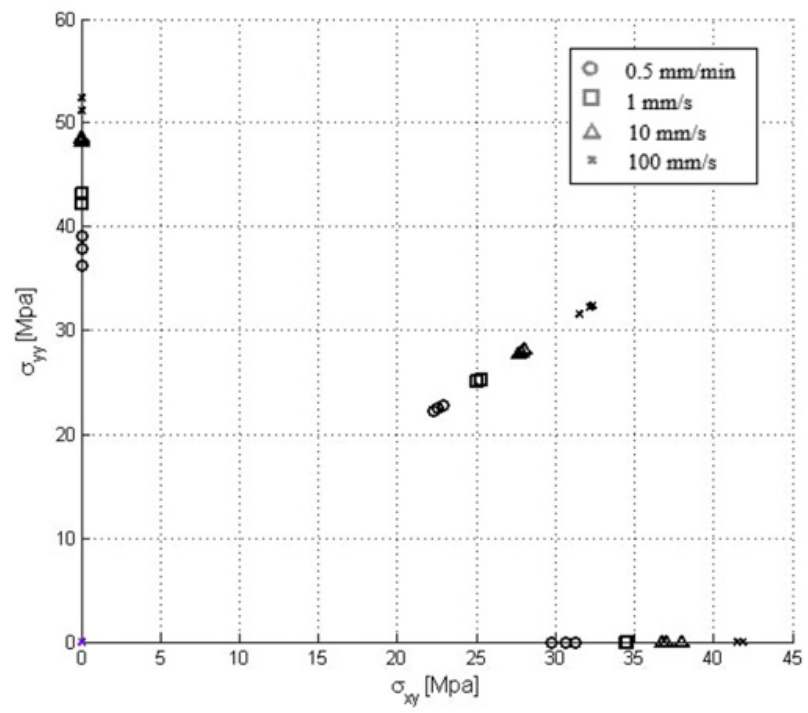

Figure 7. Failure surface.

is higher than the shear failure stress. The experimental results highlight the strain rate dependency of the failure criterion and also the loading mode dependency which could be related to the initial stress triaxiality ratio.

\section{Failure criteria}

According to these results, a new criterion based on a failure surface taking the mixed mode and strain rate dependencies into account is proposed:

$$
\left(\frac{\sigma_{y y}}{\sigma_{y y}^{\text {failure }}\left(\dot{\varepsilon}_{y y}\right)}\right)^{a}+\left(\frac{\sigma_{x y}}{\sigma_{x y}^{\text {failure }}\left(\dot{\varepsilon}_{x y}\right)}\right)^{b}=1
$$

where the parameters $a$ and $b$ give the failure surface shape. These parameters allow a better description of the criteria for mixed modes.

The strain rate effect is introduced in the tensile and shear failure stresses. Two evolution laws are used:

$$
\begin{aligned}
& \sigma_{y y}^{\text {failure }}\left(\dot{\varepsilon}_{y y}\right)=\sigma_{y y}^{0} \cdot\left(1+\left(\frac{\dot{\varepsilon}_{y y}}{\dot{\varepsilon}_{0}}\right)^{n_{y y}}\right) \\
& \sigma_{x y}^{\text {failure }}\left(\dot{\varepsilon}_{x y}\right)=\sigma_{x y}^{0} \cdot\left(1+\left(\frac{\dot{\varepsilon}_{x y}}{\dot{\varepsilon}_{0}}\right)^{n_{x y}}\right) .
\end{aligned}
$$

The strain rate value used in these equations is determined when the speed load is constant through the thickness.

Table 1 summarizes the set of parameters obtained from the model identification given by Eqs. (3-5). The fitting curves presented in Figs. 8 and 9, show the good agreement of the model chosen for the tensile and 
Table 1. Parameter of the failure criteria.

\begin{tabular}{|c|c|c|c|c|c|c|}
\hline $\mathrm{a}$ & $\mathrm{b}$ & $\sigma_{y y}^{0}$ & $\sigma_{x y}^{0}$ & $n_{y y}$ & $n_{x y}$ & $\dot{\varepsilon}$ \\
{[]} & {[]} & {$[\mathrm{Mpa}]$} & {$[\mathrm{Mpa}]$} & {[]} & {[]} & {$[\mathrm{s}-1]$} \\
\hline 2 & 1.5 & 16.56 & 12.71 & 0.04672 & 0.04839 & $1 \mathrm{e}-6$ \\
\hline
\end{tabular}

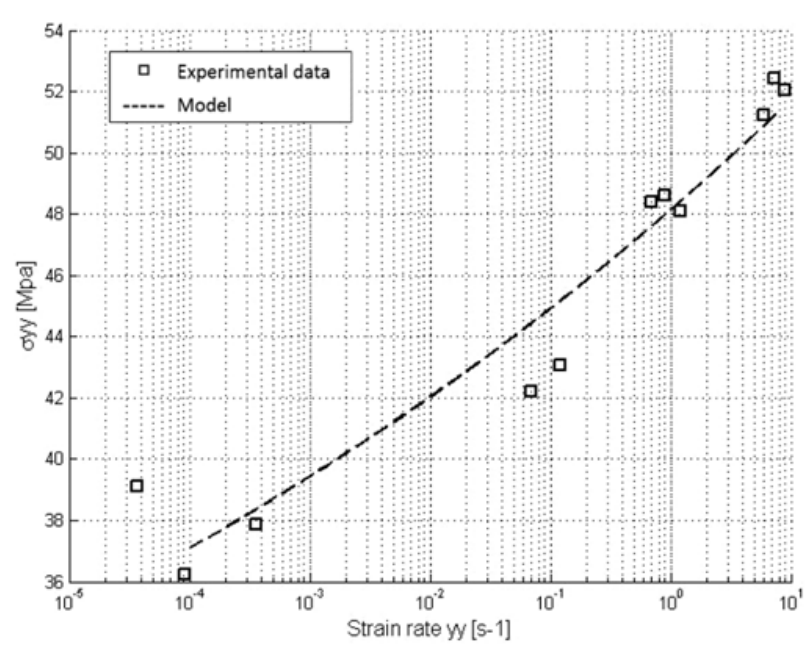

Figure 8. Strain rate dependency of the tensile failure stress.

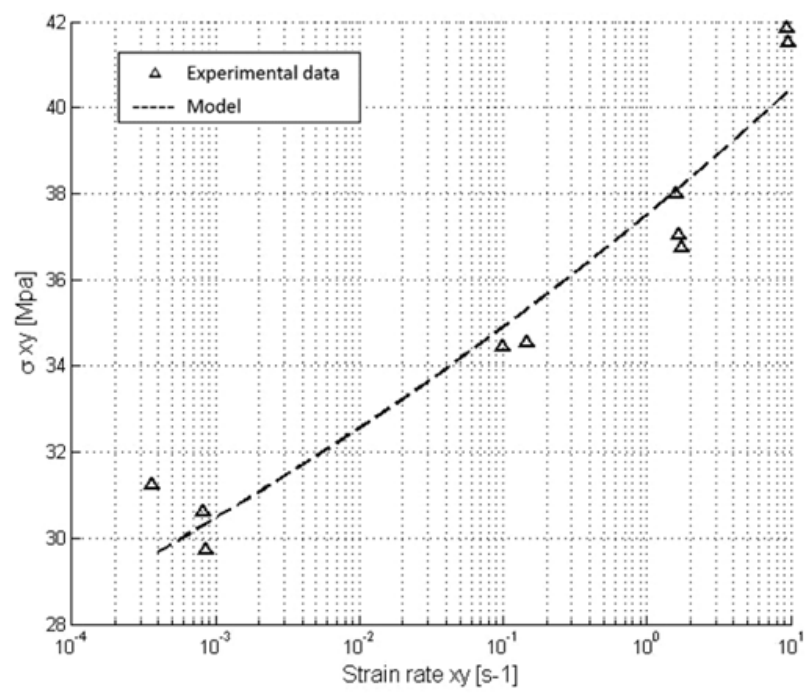

Figure 9. Strain rate dependency of the shear failure stress.

shear failure stresses evolution with the experiments. The scattering of the results is below $5 \%$ for tensile tests, and below $4 \%$ for shear tests.

Finally, Fig. 10 shows the failure stress criterion given by Eq. (3). The failure surface fits the experimental data with a maximum error of $6.6 \%$.

\section{Conclusion}

A new Arcan device is proposed to characterize the failure of bonded joints. It is designed to minimize the edge effects and to ensure a good homogeneity of the stress field in the joint.

An experimental campaign is achieved for different modes of loading and for velocities until $100 \mathrm{~mm} / \mathrm{s}$. A low scattering on the failure stresses is obtained for all the experiments. Results also highlight the strain rate and mode of loading dependencies of the failure criterion.

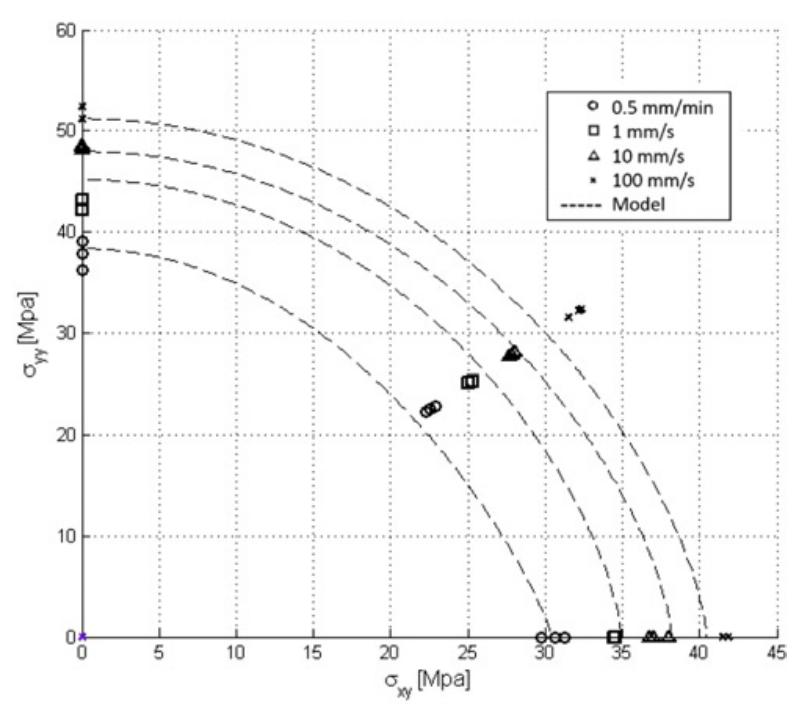

Figure 10. Failure criterion representation from $0.5 \mathrm{~mm} / \mathrm{min}$ to $100 \mathrm{~mm} / \mathrm{s}$.

Consequently, a stress failure criterion with strain rate and mode of loading dependency is proposed, and identified with this new Arcan device. The identified failure surface fits well the experimental data with a maximum error of $6.6 \%$.

In this paper, a failure criterion based on the maximum stress is proposed. This criterion will be compared in the future with other criteria based on strain or energy approaches.

The present research work call FASTLITE assembly has been supported by the "Programme véhicule du future" from Projets d'Investissements d'Avenir coordinated by ADEME, the International Campus on Safety and Intermodality in Transportation, the Region Nord Pas de Calais, the European Community, the Delegation Regionale a la Recherche et a la Technologie, the Ministere de l'Enseignement Superieur et de la Recherche, and the Centre National de la Recherche Scientifique: the authors gratefully acknowledge the support of these institutions.

\section{References}

[1] M. Bocciarelli, P. Colombi, G. Fava, C. Poggi, Eng. Frac. Mech. 76, 299-313 (2009).

[2] A. Carpinteri, P. Cornetti, N. Pugno, Eng. Struct. 31, 2436-47 (2009).

[3] L. Greenwood, London: University of London Press, 1969.

[4] K. Ikegami, T. Takeshita, K. Matsuo, T. Sugibayashi, Int. J. Adhes. Adhes. 10, 199-206 (1990).

[5] R.D. Adams, J.A. Harri, Int. J. Adhes. Adhes. 4, 6578 (1984).

[6] L.J. Hart-Smith, NASA contract report. NASA CR-112236 (1973).

[7] L.F.M. Da Silva, P.J.C. das Neves, R.D. Adams, A. Wang, J.K. Spelt, Int. J. Adhes. Adhes. 29, 331-41 (2009).

[8] V. Joudon, G. Portemont, F. Lauro, B. Bennani, Eng. Fract. Mech. 126, 166-177 (2014). 
[9] G.R. Johnson, W.H. Cook, Eng. Fract. Mech. 21, 31-48 (1985)

[10] B. Langrand, E. Markiewicz, Int. J. of Imp. Eng. 37, 792-805 (2010)

[11] D. Morin, G. Haugou, B. Bennani, F. Lauro, Eng. Fract. Mech. 77, 3481-3500 (2010).
[12] D. Morin, G. Haugou, B. Bennani, F. Lauro, Int. J. Adhes. sci. and Tech. 25, 1581-1602 (2011).

[13] D. Morin, B. Bourel, B. Bennani, F. Lauro, D. Lesueur, Int. J. of Imp. Eng. 53, 94-105 (2013).

[14] J.Y. Cognard, P. Davies, B. Gineste, L. Sohier, Comp. Sci. and Tech. 65, 359-368 (2005). 